\title{
ON BECOMING EDUCATOR-CHANGEMAKERS
}

\author{
Kai Zhuang, Franz Newland \\ Lassonde School of Engineering, York University, Canada \\ kai.zhuang@lassonde.yorku.ca
}

\begin{abstract}
Today's world has an urgent need for engineer-changemakers to participate in the addressing of complex societal challenges. However, today's Engineering Education does not provide the opportunity for students to develop the necessary skills, perspectives, and experiences to become engineer-changemakers. In this paper, we present a new model of changemaking and use this model to assess the profession of engineering, engineering education, and a number of initiatives we have created over the past year at the Lassonde Futures Lab. Using the model, we also propose a forward thinking vision for creating a "purpose-driven collaboratory" that simultaneously catalyzes change and prepares changemakers.
\end{abstract}

\section{Keywords: Learning journeys, Changemaking, Changemaker, Engineering and society, Interdisciplinary collaboration}

\section{INTRODUCTION}

The complex challenges we face as a society - from climate change to advanced automation, from economic disparity to social conflicts and alienation - are inextricably related to creation, usage, and evolution of technology. If we as engineers are to participate in addressing these challenges - and there is an urgent societal need for us to do so - we must evolve beyond our focus on technical development and commercial success, and become much more involved in the social and environmental dimensions of our work. Equally critical is to do so from a place of wisdom and humanity. Those leading this change are, in our terminology, "engineerchangemakers".

Today, "engineer-changemakers" are still a minority in our discipline. As engineering-educators, we have observed a great and rising interest from our students for becoming "engineering-changemakers", but our technically focused engineering curriculum provides very little opportunity to engage this interest. More importantly, the culture of engineering education is almost antithetical to the spirit of change-making. Not only do we train students to become conventional engineers to serve an existing status quo, we as educators often model behaviours belonging to this status quo, making it culturally difficult for students to become engineer-changemakers.

Over the past two years, we have explored a number of educational initiatives and pathways to accompany the journeys of would-be "engineer-changemakers" in the Lassonde School of Engineering [1]. Additionally, we have participated extensively in the Engineering Change Lab, a large-scale change-making initiative that seeks to unleash the higher potential of engineering profession and community [2]. Based on these and other experiences and learnings, we are developing a new model of changemaking involving five intertwined journeys - the journeys of purpose, collective, self, action, and knowledge - and propose that these journeys are the necessary components of an engineer-changemaker's education.

In this paper, we will present the five-journeys model and discuss the current state of engineering and engineering education in light of this model. We will also discuss our ideas on how today's engineer-educators can use this model to create educational experiences and environments that are conducive to the development of engineerchangemakers, and in the process become "educatorchangemakers". Finally, we will share our current vision for creating a "five-journeys collaboratory" that simultaneously catalyze change-making and educate change-makers.

\section{FIVE JOURNEYS \& POST- CONVENTIONAL CHANGEMAKING}

Today, there is a broad recognition for the importance and urgency of complex challenges related to people, society, technology, and the environment. The conventional approaches to address these challenges are reductionist and segmented, resulting in changes that are incremental instead of transformative. As an example, consider a scenario where an engineer develops a breakthrough solar technology on the same day an environmental activist publishes a visionary manifesto on creating a solar energy society: despite the obvious synergy between their works, these two people would not meet and exchange ideas because they are from two very different worlds. The two 
may go on to transform their respective fields, and their ideas may eventually interact, but by then, it may be too late for the planet. This scenario, contrite as it may be, is illustrative of the deficiencies in the conventional approaches. Moreover, the conventional solution to complex challenges tend to be ethno-centric (i.e. benefiting some, but not all) [3] due to the homogenous perspective involved in the creative process. What is needed is a new approach to complex challenges involving capable of generating transformative and universal-caring (i.e. benefiting all) [4] solutions.

From our experiences in and observations as educators and change catalysts, we posit that beneficial changes to society originates from the following five sets of questions:

1. Questions about purpose: What kind of world do we want? Why do we want it?

2. Questions about the collective: Who are we? How do we ally with each other?

3. Questions about the self: Who am I? How do I lead?

4. Questions about actions: What do we sense? What do we do?

5. Questions about knowledge: What do we know? What can we do?

We see the exploration of each set of questions as a distinct changemaking journey; as such, we posit that beneficial societal changes are conceived and implemented through five journeys: the journey of purpose, collective, self, action, and knowledge. It is our belief that in order to generate transformative solutions that benefits all, it is optimal for a diverse group of changemakers to partake in these fives journeys together around a complex challenge with universal-caring intentions - this is the essence of the "five journeys" model of post-conventional change making [Figure 1].

Initially, we had envisioned these journeys as intertwined journeys to be traveled in parallel. Upon further exploration, we noticed two distinct relational patterns amongst the journeys: When the five journeys proceed in balance, a generative cycle where the outcome of one journey catalyzes the next journey is created. For example, environmentalism (as a purpose) is made more concrete when supported by knowledge about the environment; A clear articulation of this purpose is then able to call to a more diverse group to work on problems of environmental sustainability. However, when we over-emphasize one journey, an inhibitory cycle is created. For example, when we over-emphasize the knowledge journey in academia, we create silos of "absolute truths", even inside interdisciplinary settings, and this prevents the diverse perspectives from surfacing in the journey of collective.
The patterns of the catalytic and inhibitory relationships are presented in Figure 2 in an overlaid format. The rationality for the patterns are illustrated in Figure 3.

\section{ENGINEERING: A GAME OF TWO JOURNEYS}

Mindful of the audience of this paper, we will limit the theoretical discussion of the model to the summary above. In this section, we will use the model to understand the failings of engineering and engineering education. In our experience, the engineering profession is primarily concerned about two journeys (Figure 4A): the development and improvement of technology (knowledge journey) and the implementation of technology, particularly for business reasons (action journey). Typically, engineers forgo the purpose journey, either operates with little care for big-picture societal purpose, or with an assumed purpose associated with his/her specialization. For example, an electrical engineer may assume that her purpose is to develop electronic technologies because that is her specialization. Without a greater purpose, engineers rarely form collectives, and are rarely driven to engage in personal growth. Engineers that are particularly focused on technical work (emphasizing the knowledge journey) can become dismiss of nonengineers and non-engineering perspectives, at least when operating in a professional capacity.

In our opinion, it would be ideal for both the engineering profession and engineering education to travel all five journeys. The situation in engineering education, as a generalization, is further from this goal than the situation in the profession. Typically, an engineering student would focus solely on the journey of knowledge, forgoing the journeys of purpose, collective, and self, and only occasionally experience real-world actions via capstone projects (Figure 4B). This heavy emphasis on the knowledge journey creates a silo-ed experience, and inhibits the collective journey. Students would pay little attention to non-engineering perspectives and neglect the development of empathetic and communicative skills because they do not see the importance of working with none engineers. Although there are group projects, they do not constitute a "collective journey" experience because they are sourced in a singular disciplinary perspective and rarely involve collective growth.

\section{EDUCATING ENGINEER- CHANGEMAKERS}

Recognizing the importance of Engineer-Changemakers and these gaps in the necessary purpose, collective and self journeys demands us to reflect on our role as educators to help facilitate student growth in these directions. 
Considering the graduate attributes required of engineering accreditation today, some engineering faculty find they are not necessarily well equipped to support or assess some of the expected skills, such as communications, lifelong learning or the societal impacts of engineering. Some engineering schools have made use of co-teaching with other faculties who have such expertise to address these aspects of graduate aspects, but this requires engineering and non-engineering faculty to work closely together, to understand each others' areas of expertise sufficiently to have a successful collaboration. In the case of engineer changemakers, the growth of a cohort and its members, and the identification and growth of purpose, requires accompaniment in a number of different domains, that again may not overlap very closely with interests or capacities of traditional engineering faculty. Further than this, some of the areas of exploration are best accompanied by people outside academia. In some engineering courses, guest speakers from industry, government or social enterprises are called upon, but finding people to accompany a cohort as facilitators with a core goal of universal care is a different proposition.

Two pathways are proposed to taking early steps to addressing some of these gaps. To help identify appropriate accompanists, a set of principles for the accompanist group may be appropriate. The commitment to considering universal care as the goal is foundational, and drives the educator to seek provocation and support for broad, diverse perspectives of the societal benefits and challenges of the educational purpose. This requires the educator themselves to be open to such provocation, and to have support. To facilitate the collective growth journey, a commitment to, and space for, collaborative teaching is likely very important, both for modelling the collective growth and to have diverse voices amongst the educators. The intention of the educators to themselves grow and develop the education journeys is also key. The second, parallel, pathway presented consists of some early experiments into activities that may develop the broader journey. These are discussed in the next section.

\subsection{Example: Lassonde Futures Lab}

As an early part of our reflection on building Engineering Changemakers in the Lassonde School of Engineering at York University, we developed a three-phased approach consisting of curricular experiments, extra-curricular experiences and underlying research to inform the activities. The Lassonde Futures Lab (LFL) was created in Summer 2017 through support funding from the Dean's office to act as a focal point for several activities already happening within the Lassonde school under the Renaissance Engineering ${ }^{\mathrm{TM}}$ identity. The activities were aimed at giving students opportunities to break down the barriers between traditional engineering disciplines and the rest of society. There was particular emphasis on

- artistic and creative activities,

- those that connect social and human needs and consequences to engineering endeavors and

- those that involve cross-disciplinary opportunities with disciplines outside the school.

The goals of bringing these activities under the one, common LFL umbrella, were to allow the synergies to be found between the activities and provide an easier means for students to identify and engage with the activities. LFL has also found inspiration from Lassonde's involvement in the Engineering Change Lab (ECL) - a group of government, industry, academia and K-12 partners looking at the question of how to unlock the potential of the Engineering Community. Many of the ideas within the ECL community centre around breaking down barriers between the existing engineering profession and the rest of society, with groups considering how to address the diversity challenges, the future of engineering education, the potential for engineering leadership, creating work spaces ready for the next generation of engineering thinking etc. Compared to ECL, LFL is trying to create spaces to explore the educational landscape assuming some of the transitions sought by ECL have already happened what could the learning landscape look like once the system has changed to the model many in the community have identified the need for? The five-journeys theory has been developed in part as a result of some of the reflections on the early LFL experiments. In this section, we reflect on some of the experiences and limitations of these experiments using the new five journeys framework.

Curricular components explored include the Passion Project, a 1-credit course offering that can be taken at any point in a student degree. It gives students a structured opportunity to explore anything they are passionate about. Through its three iterations, projects have tackled a wide range of themes, and the first passion project exhibition was very well attended. At the same time, the transformational experience has not necessarily continued outside the course. Reflecting on the five journeys, although the projects are intended to be meaningful, without a galvanizing central purpose, the collective journey has been more limited, resulting in some projects struggling without sufficient collective support and other projects failing to achieve their higher potential without sufficient collective provocation. The lack of a strong "universal care" framing has also created some student focus on passion of a "technology push" which can result in a project with limited final societal purpose. As such, whilst many of the students who have taken the course have had very positive reflections on the experience, confirming the need for such a space for at least some of the student population, the change experience has not yet been as intentional as it could be. Reflection elements on humanity 
in engineering have also been added to a number of the common engineering courses. These have addressed the knowledge-to-purpose components of the five journeys model, but have not resonated for all students in the class. This needs further exploration, to get to a common purpose for the community, and to better understand and absorb the diversity of engagement in the class. See Figure 5A for an illustration of the Passion Project using the five journeys model.

In terms of extra-curricular activity, a creativity workshop series has given students in Lassonde a space to explore pottery, painting and baking, capturing clay interpretations of what Lassonde means to them and painted images of the Bergeron centre. The evening workshops have been very well attended and resulted in some impressive pieces of art. The anecdotal feedback from the events included one student who reflected on the fact that they would not underestimate arts students again, having found the activity challenging, but rewarding. A music maker fare was also trialled during summer 2017, conceived as a 2-day activity for music and engineering students. Day 1 was designed to focus on building electronic instruments and day 2 was planned to focus on composing a piece for the instruments and performing it. Due to some scheduling difficulties, the trial-run had to be compressed to a single day. The students worked in two teams and each built an Arduino-based instrument (one using a tonal scale and one combining lights and a chromatic scale instrument). Anecdotally, the music students began the activity quite concerned about their ability to participate and ended the day with a number of ideas about how they could incorporate low-cost electronics into their future musical activities. The composition activity was not run in the trial day, but the Lassonde student already commented on the fact they had not even considered different musical scales might exist. The second of these activities worked well in the purposecollective-self tourney space. Participants were drawn to the possibility of breaking down barriers between technology and music, and some collective understanding and growth was seen, resulting in individuals being provoked and supported to head in new directions. In the absence of specific spaces for students to explore taking action to develop new knowledge to better inform the initial purpose, the cycle did not complete, however the activity was very successful at traversing the right-hand side of the five journeys. A similar pattern was seen in The Explorer's Café activity, a set of evening talks and discussions inspired by one of the Engineering Change Lab's concepts of "what is the change in the world we want to see, and what will I change in myself to help get there?". The talk series has consisted of a provocation piece from which the participants co-create a position of some common purpose related to the provocation, considering what this might look at a global scale, a regional scale, an organizational scale and a local scale, before identifying specific changes we can all take to start heading towards the common purpose. As stand-alone evening talks, these have been quite successful, with many students attending on a regular basis. The purpose, collective and self-growth paths have been exercised, however the steps to action and spaces to exercise the action, new knowledge and growth in purpose have again been more limited.

In transitioning to the second year of LFL activities, we are exploring how to develop the existing experiments and add new ones, to help implement all five journeys in sequence. The framing of LFL itself will be grown from its current curricular/extra-curricular/research lenses to shift to the five journeys framing, with explicit consideration of purpose, community, self, action and knowledge within the lab.

\section{A PURPOSE-DRIVEN COLLABORATORY}

Looking beyond LFL activities, we envision a purposedriven "collaboratory" (co-creative laboratory) built on the "five journeys" theory as a space that serves the dual purposes of facilitating collaborative changemaking and preparing future changemakers. The collaboratory would operate in a cohort mode, with each cohort working on a specific purpose. The cohort purpose needs to be based on a real world complex challenge and framed with an intention of universal-caring (doing good for all). It can be as broad as "safety in society" and "global food sustainability". Narrower and more local purposes such as "thriving after a local earthquake" could also work as long as it is framed with sufficient breadth to draw in a diverse cohort. The cohort would consist of a changemaker group purely interested in solving the complex challenge at hand and a learner group interested in exploring how to do postconventional changemaking. The cohort will travel the five journeys together, with the collaboratory providing facilitations for each journey. In some ways, there are similarities between the proposed collaboratory and "social labs" [2]; however, the social labs approach does not make the five journeys explicit, and therefore can at times neglect one or more journeys. Currently, we are exploring the possibility of developing the first collaboratory of this kind at the upcoming York University Markham campus.

\section{Acknowledgements}

We acknowledge support from Lassonde School of Engineering, York University.

\section{References}

[1] Kai Zhuang and Franz Newland, "Engineering the Future: A Conceptual Framework for Evolving Engineering Education," in Proc.CEEA Canadian Engineering 
Proc. 2018 Canadian Engineering Education Association (CEEA-ACEG18) Conf.

Education Association Conference 2018, 2018

[2] Zaid Hassan, The Social Labs Revolution: A New Approach to Solving our Most Complex Challenges. San Fransisco, CA: Berrett-Koehler Publishers, 2014. \{ISBN: 978$1626560734\}$
[3] Ken Wilber, A Sociable God: Toward a New Understanding of Religion. Shambhala, 2005. \{ISBN: 978-1590302248\}

[4] Carol Gilligan, In a Different Voice: Psychological Theory and Women's Development. Harvard University Press, 1993. \{ISBN: 978-0674445444\}

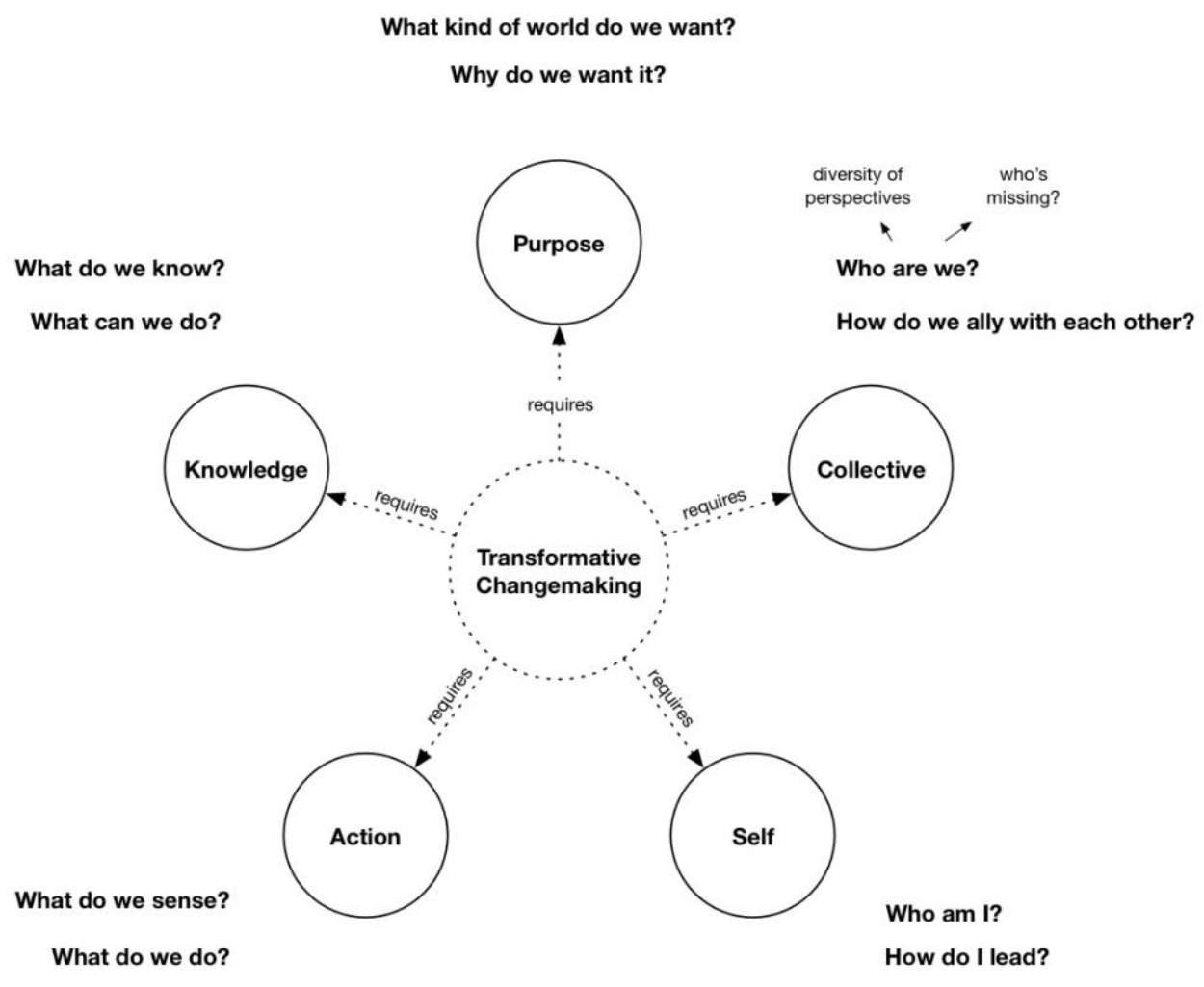

rCEEA18; Paper 85

University of British Columbia; June $3-6,2018 \quad-5$ of $9-$ 
Figure 1: Five journeys required for transformative changemaking.

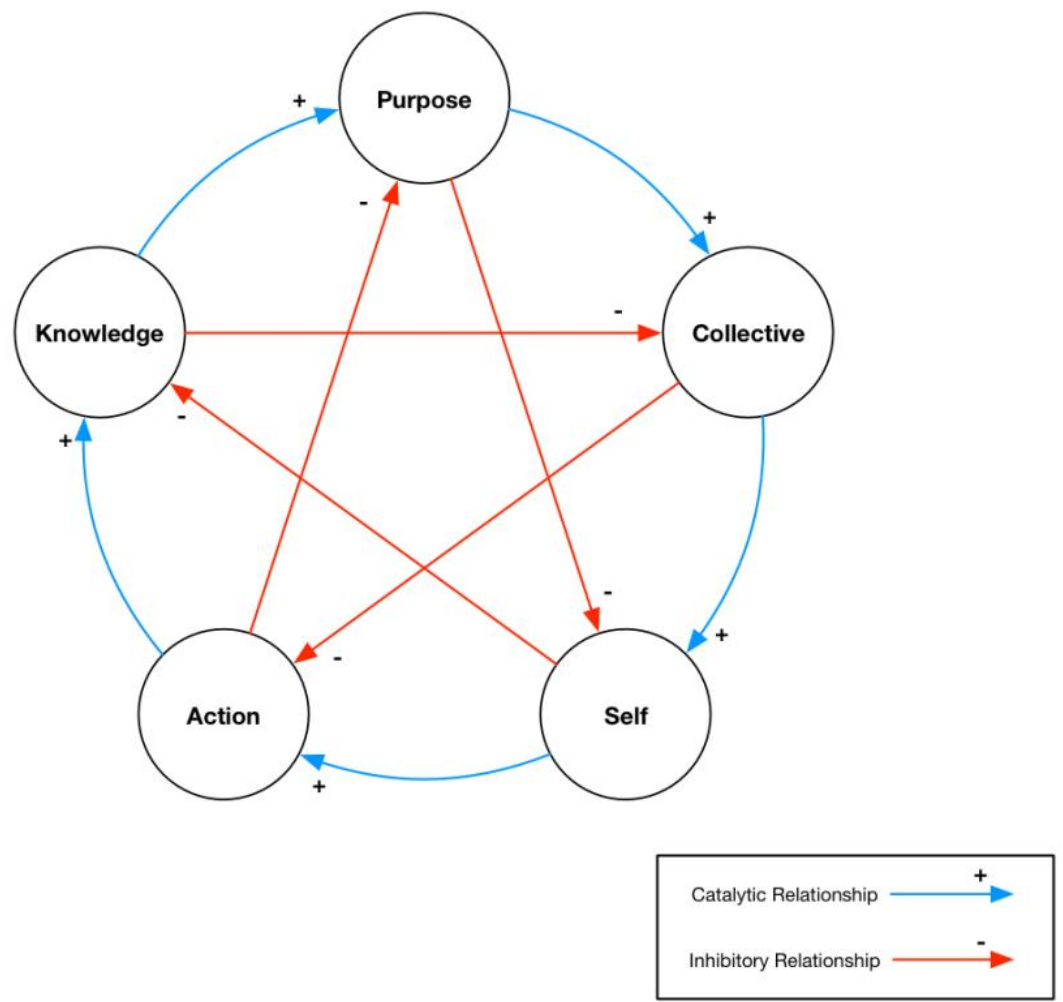

Figure 2: The catalytic and inhibitory relationships among the five journeys. 
A

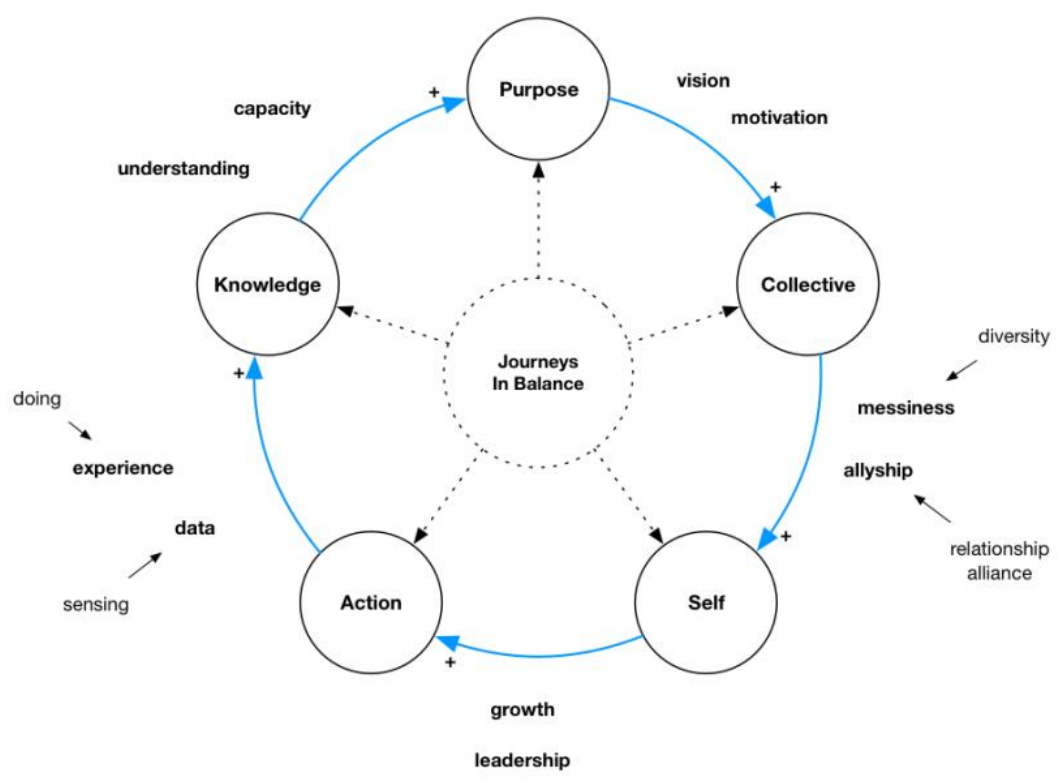

B

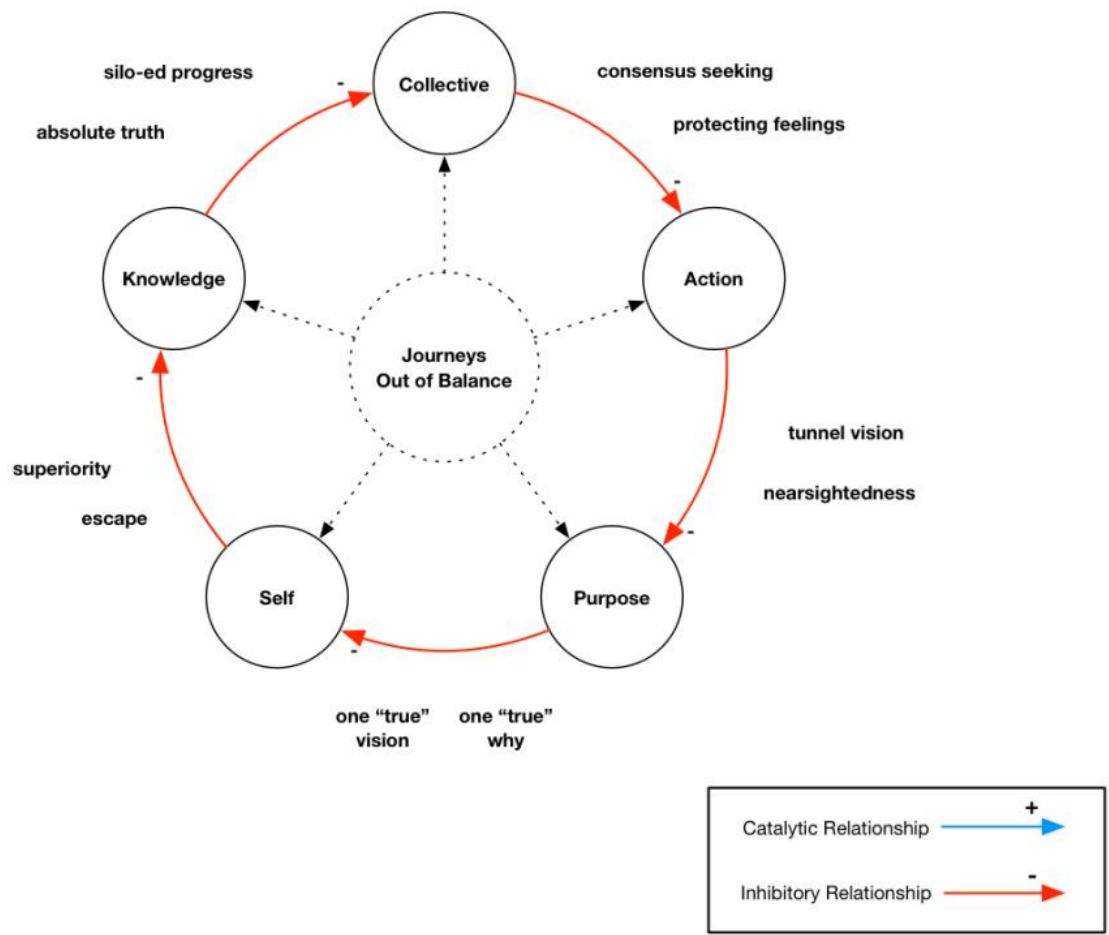

Figure 3: The reasoning behind the catalytic and inhibitory cycles. 
A: The Engineering Profession

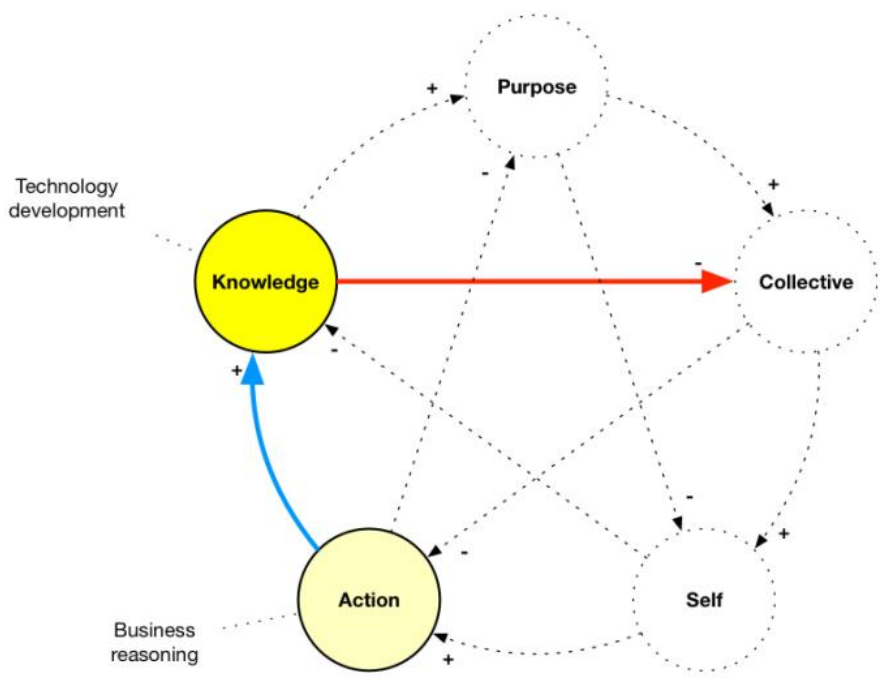

B: Engineering Education

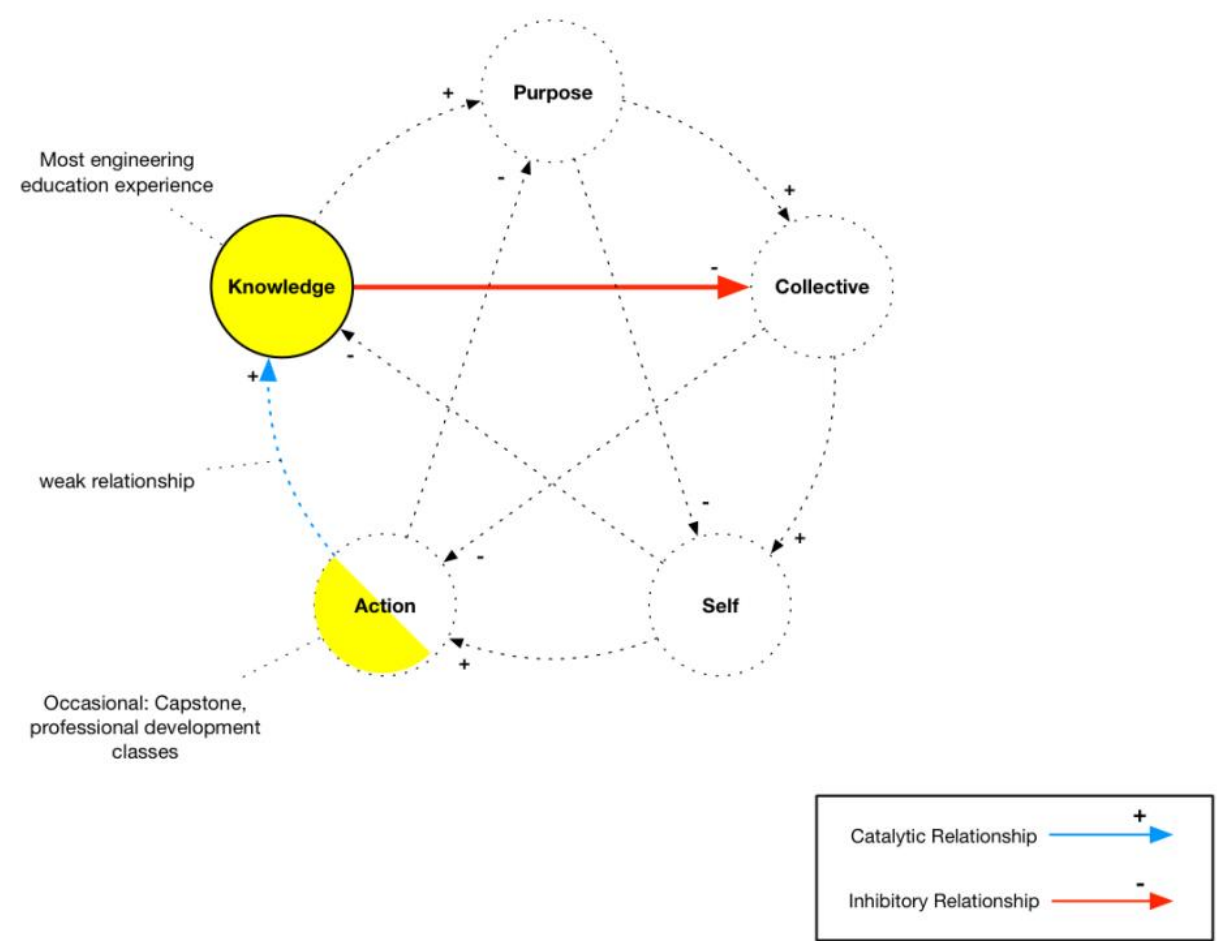

Figure 4: Using the "five journeys" to explore Engineering and Engineering Education. 

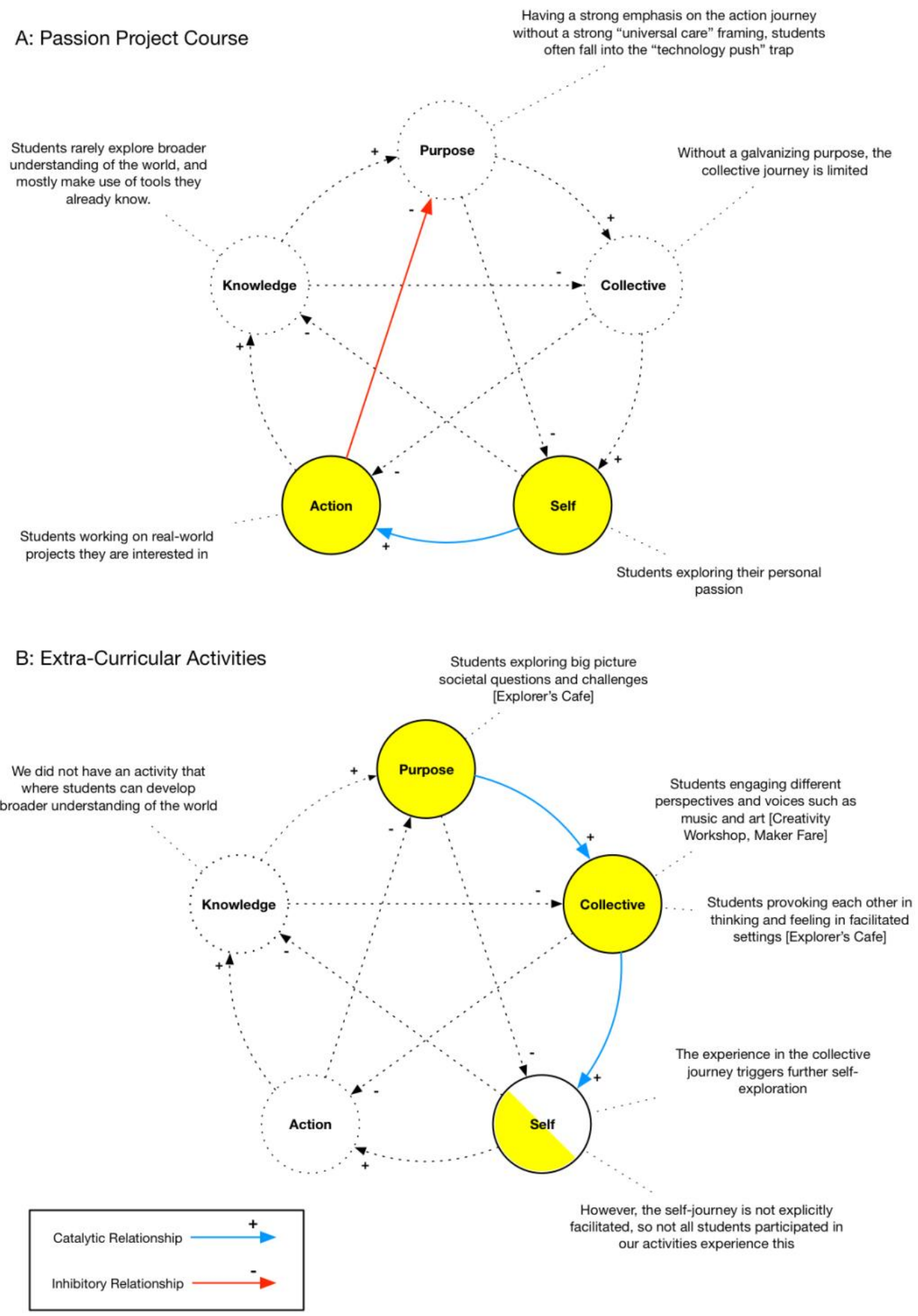

Figure 5: Using the "five journeys" to explore Lassonde Futures Lab educational initiatives 